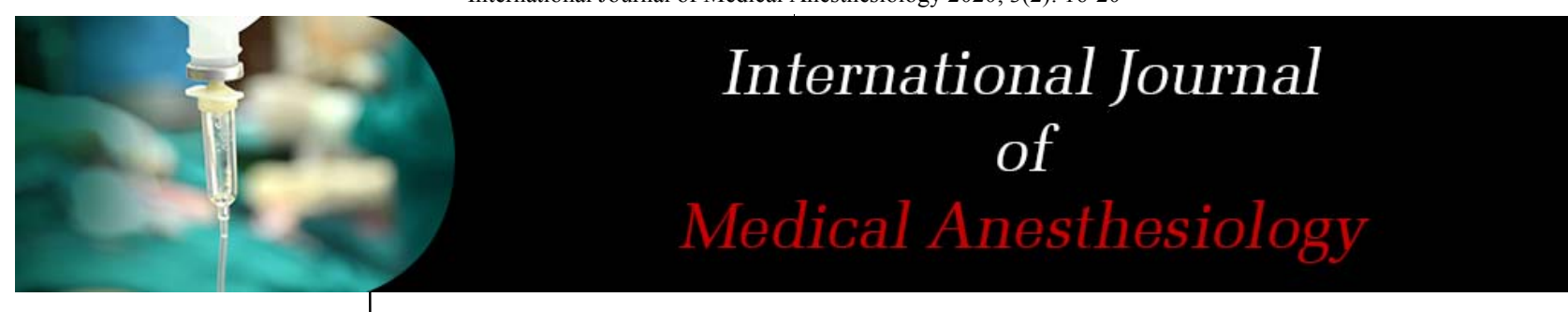

E-ISSN: 2664-3774

P-ISSN: 2664-3766

www.anesthesiologypaper.com

IJMA 2020; 3(2): 16-20

Received: 11-01-2020

Accepted: 15-02-2020

Dr. Krishna Sagar SR

Senior resident,

Department of

Anaesthesiology, BMCRI,

Bangalore, Karnataka, India

Dr. Ravi Bhat

Professor,

SDM college of medical

sciences and hospital

Dharwad, Karnataka, India

Dr. Raghavendra Rao SDM college of medical sciences and hospital

Dharwad, Karnataka, India

Corresponding Author:

Dr. Ravi Bhat

Professor,

SDM college of medical

sciences and hospital

Dharwad, Karnataka, India

\section{Comparison of post-operative analgesic effects of intrathecal nalbuphine and intrathecal clonidine in patients undergoing elective lower limb orthopaedic surgeries: A prospective randomized double blind study}

\author{
Dr. Krishna Sagar SR, Dr. Ravi Bhat and Dr. Raghavendra Rao
}

DOI: https://doi.org/10.33545/26643766.2020.v3.i2a.117

Abstract

Background The aim of the study was to compare the analgesic duration of both intrathecal nalbuphine and intrathecal clonidine.

Materials and Methods 99 patients undergoing lower limb orthopedic surgeries randomized into 3 groups comprising 33 patients in each. They were randomly allocated into - 0.5\%hyperbaric bupivacaine $(2.6 \mathrm{ml}$ ) with $0.4 \mathrm{ml}$ of Normal saline control group(GroupZ), $0.8 \mathrm{mg}$ nalbuphine(Group N), $0.4 \mathrm{ml}$ of $60 \mu \mathrm{g}$ clonidine(Group C). The analgesic duration evaluated using VAS.

Results The analgesic duration in control group $212.97 \pm 16.33$ min compared to $377.06 \pm 33.89$ min in nalbuphine group \& $493.55 \pm 173.54$ mins in clonidine group. Diclofenac consumption maximum at the $4^{\text {th }}$ hour in control group, $8^{\text {th }}-16^{\text {th }}$ hour in the nalbuphine group. It was at the $16^{\text {th }}$ hour in the clonidine group.

Conclusion intrathecal clonidine $60 \mu \mathrm{g}$ provided better post operative analgesia compared with nalbuphine.

Keywords: nalbuphine; Clonidine; Bupivacaine; Analgesia; Visual analog scale

\section{Introduction}

Subarachnoid block is a neuraxial block involving injection of opioids, local anaesthetics or other permissive drugs into the subarachnoid space ${ }^{[1]}$. Spinal anaesthesia can be used to provide surgical anaesthesia for all procedures carried out on the lower half of the body ${ }^{[2]}$. $\mathrm{SAB}$ is the most convenient anaesthetic technique that offers reduced stress response and improved pain relief ${ }^{[3]}$.

Bupivacaine is the most commonly used local anaesthetic agent for spinal anaesthesia. It is cardiotoxic, but the doses used in spinal anaesthesia (maximum $20 \mathrm{mg}$ ) are far too small to cause cardiotoxicity ${ }^{[4]}$. Intrathecal opioids are synergistic with local anesthetics and intensify the sensory block without increasing the sympathetic block. They also prolong the post operative analgesic duration ${ }^{[5]}$.

Nalbuphine is a lipophilic semi-synthetic opioid related to both oxymorphone and naloxone. Nalbuphine has relatively potent $\mu$-antagonist and $\kappa$-agonist activity. $\kappa$-opioid receptors are involved in nociception, which are distributed throughout brain and spinal cord. Nalbuphine avidly binds to $\kappa$-receptors in the brain to produce analgesia. The $\mu$ - antagonist properties of nalbuphine produce less side effects such as respiratory depression, pruritus, nausea and vomiting. This defines nalbuphine as a mixed agonist-antagonist ${ }^{[6]}$.

Clonidine, a selective partial $\alpha_{2}$-adrenergic agonist. It is a potent analgesic, free of opioidrelated side effects. The anatomic site of action of the $\alpha_{2}$ - agonists involves specific receptors of the spinal dorsal horn and supraspinally in the nucleus coeruleus in the pons. The mechanism and location of action of the sedative effect of these compounds are due to the hyperpolarization of excitable neurons localized in the nucleus coeruleus. Their supraspinal analgesic mechanism in the locus coeruleus is probably by transduction, while in the spinal cord is likely related to the activation of the descending medullospinal noradrenergic pathways or the reduction of spinal sympathetic outflow at presynaptic ganglionic sites ${ }^{[7]}$. 
Intrathecal clonidine is being extensively used as an alternative to neuraxial opioids for control of pain and has proven to be a potent analgesic, free of some of the opioidrelated side effects ${ }^{[8]}$.

There has been a dearth of studies in the literature comparing the benefits and potential side effects of the intrathecal nalbuphine and clonidine as potential adjuvants to $0.5 \%$ hyperbaric bupivacaine for elective lower limb orthopedic surgeries. Therefore, we have undertaken this study to investigate and compare intrathecal nalbuphine and clonidine as an attractive adjuvant to $0.5 \%$ hyperbaric bupivacaine for the efficacy of motor and sensory blockade, haemodynamic stability, post-operative analgesic requirements and side effects.

\section{Objectives}

Primary objective of the study is to compare the postoperative analgesic duration of IT nalbuphine or IT clonidine as an adjuvant to $0.5 \%$ hyperbaric bupivacaine in patients undergoing lower limb orthopedic surgeries.

Secondary objectives are to compare the haemodynamic response of the adjuvants, Adverse effects, if any, Postoperative recovery time, Post-operative consumption of ondansetron, Post-operative consumption of rescue analgesic (diclofenac).

\section{Methodology}

This prospective, randomized, double blind interventional study was carried out in the department of anaesthesiology, SDM College of Medical Sciences and Hospital, Dharwad from December 2015 to May 2017 with the permission from hospital ethical committee along with well-informed written consent from all patients undergoing elective lower limb orthopaedic surgeries requiring sub-arachnoid blockade as a modality of anaesthesia.99 patients were included randomly based on sealed envelope method into three study groups comprising 33 patients in each.

All the patients falling under inclusion criteria were numbered and the patients were randomly allocated into either nalbuphine group (Group N), clonidine group (Group C) or control group (Group Z) using sealed envelope technique.

All the patients were kept nil-per-oral overnight and premedicated with oral diazepam $5 \mathrm{mg}$ on the previous night of surgery. No analgesic was given on the day of surgery before taking to OR. At the pre-operative visit, patients were familiarized with the recording of post-operative pain using a $10-\mathrm{cm}$ visual analogue sale (49) anchored at one end by "no pain at all "and at the other end by "worst pain imaginable."

The patients were randomly allocated into nalbuphine group (Group N), Clonidine group (Group C) or control group (Group Z) using sealed envelope technique into three groups of 33 each, which was opened just before shifting the patient to the operation theatre.

1. Group $\mathrm{Z}:-2.6 \mathrm{ml}$ of $0.5 \%$ hyperbaric bupivacaine and $0.4 \mathrm{ml}$ of Normal saline.

2. Group N: $-2.6 \mathrm{ml}$ of $0.5 \%$ hyperbaric bupivacaine and $0.4 \mathrm{ml}$ of $0.8 \mathrm{mg}$ nalbuphine.

3. Group C: $-2.6 \mathrm{ml}$ of $0.5 \%$ hyperbaric bupivacaine and $0.4 \mathrm{ml}$ of $60 \mu \mathrm{g}$ clonidine.

In the operation theatre, an appropriate i.v. access was secured and i.v fluids started.

Standard monitoring with electrocardiogram, noninvasive arterial blood pressure (NIBP) and pulse-oximetry was initiated and baseline values were recorded. The patients were administered $2.6 \mathrm{ml}$ of $0.5 \%$ bupivacaine hyperbaric with the adjuvant. The sterile drug solution was prepared by an experienced and trained anesthesiologist, who is not involved in intraoperative and postoperative management. Anaesthesia resident doing the study was blinded for the study drug being injected.

Under strict aseptic precautions, the subarachnoid blockade was performed with a $26 \mathrm{G}$ Quincke spinal needle in the L3L4 interspace in sitting position. The preloaded sterile drug solution was injected over 10-15 seconds after confirmation of free aspiration of cerebrospinal fluid (CSF). The time at which the preloaded sterile drug solution was completely injected into the sub-arachnoid space was noted as the zero time of the study and all subsequent measurements were recorded from this point. Following the administration of the subarachnoid block, the patients were made to lie down supine. Sensory testing was done by cold swab method using cotton swab and time taken to reach $\mathrm{T}_{10}$ level noted. Motor block assessed using modified Bromage Score.

The time taken to reach modified Bromage 3 was recorded. Intravenous ephedrine $6 \mathrm{mg}$ was administered if the systolic blood pressure reduction was $\geq 20 \%$ of the baseline value or if the MAP was $\leq 60 \mathrm{~mm} \mathrm{Hg}$. Intravenous atropine $0.6 \mathrm{mg}$ administered if the HR was $\leq 50 \mathrm{bpm}$. Patients did not receive any additional analgesic in intra-operative period while anxious patients were given intravenous midazolam $1 \mathrm{mg}$. The incidence of any adverse effects such as hypotension, bradycardia, shivering, nausea, vomiting, pruritus, respiratory depression and ECG changes were noted. If there was inadequate or failed spinal, the duration of surgery extended more than $120 \mathrm{~min}$ or if the patients complains of pain, they were excluded from the study.

All the patients were monitored in the post anaesthesia care unit (PACU) for two hours. In the PACU, inj. Diclofenac 75 $\mathrm{mg}$ i.v was administered if the patient complained of pain and had visual analogue scale $\geq 5$. Second line of analgesic inj. tramadol $50 \mathrm{mg}$ slow i.v was administered, if VAS scale did not come below 3, after 30 min administration of inj. Diclofenac $75 \mathrm{mg}$. If any nausea or vomiting, treated with IV ondansetron $4 \mathrm{mg}$

Duration of analgesia was taken from the time of intrathecal drug administration to the first supplementation of rescue analgesic when the patient complained of pain or visual analogue scale $\geq 5$.

\section{Modified Bromage Scale}

0 . No motor block

1. Inability to raise extended leg; able to move knees and feet

2. Inability to raise extended leg and move knee; able to move feet

3. Complete block of motor limb

\section{Statistical Analysis}

The statistical software SPSS 25.0 (2017) for windows, was used for the analysis of the data and Microsoft word and Excel have been used to generate graphs, tables etc.

\section{Results}

The data was collected and statistical analysis was performed as explained in the methodology of the study. The results were as follows; 
All the patients in three groups were comparable with respect to the gender, age, weight and ASA physical status.

The mean duration of anaesthesia and surgery were comparable in both the groups.

The time to reach maximum sensory level in Nalbuphine group (9.73 $\mathrm{min}$ ) was more compared to both control group
(6.73 $\mathrm{min})$ and clonidine group $(6.36 \mathrm{~min})$ and it is statistically very highly significant (Table 1 ).

The time to reach maximum motor level in Nalbuphine group (6.76 $\mathrm{min}$ ) was more compared to both control group (4.61 $\mathrm{min})$ and clonidine group (4.58 $\mathrm{min})$ and it is statistically very highly significant (Table 1$)$.

Table 1: Comparison of three study groups with respect to mean time to reach maximum sensory level (in min) and time to reach complete motor block (in min) by one-way ANOVA

\begin{tabular}{|l|l|l|l|l|l|}
\hline Variables & Summary & Control group & Nalbuphine group & Clonidine group & P value \\
\hline Time to reach max sensory level (in min) & Mean (SD) & $6.73(2.54)$ & $9.73(3.06)$ & $6.36(2.13)$ & $0.0001 *$ \\
\hline Time to reach complete motor block (in min) & Mean (SD) & $4.61(1.54)$ & $6.76(2.26)$ & $4.58(1.39)$ & $0.0001 *$ \\
\hline
\end{tabular}

Time for two segment regression was more in the clonidine group (209.06 min) compared to nalbuphine group (175.33 min) and control group (108.73min) (Table 2). The difference was very highly statistically significant $(p<0.0001)$.

Time for motor blockade regression to modified Bromage 0 was longer with clonidine group (213.06 min) compared to
Nalbuphine group (175.06 min) and control group (186.39 $\min )$. The difference was very highly statistically significant $(p<0.0001)$ (Table 2).

The duration of analgesia was more in the clonidine group (493.55 min) compare to Nalbuphine group (377.06 $\mathrm{min}$ ) and control group (212.97 $\mathrm{min})$, which was very highly statistically significant (Table 2) .

Table 2: Comparison of analgesia in the clonidine group

\begin{tabular}{|c|c|c|c|c|c|}
\hline Variables & Summary & Control group & Nalbuphine group & Clonidine group & P value \\
\hline Time for two segment sensory regression (in min) & Mean (SD) & $108.73(19.51)$ & $175.33(42.78)$ & $209.06(56.06)$ & $0.0001^{*}$ \\
\hline $\begin{array}{c}\text { Time for duration of motor blockade(min) } \\
\text { regression to Bromage 0 }\end{array}$ & Mean (SD) & $186.39(32.42)$ & $175.06(33.33)$ & $213.06(40.35)$ & $0.0001^{*}$ \\
\hline Duration of analgesia (in min) & Mean (SD) & $212.97(16.33)$ & $377.06(33.89)$ & $493.55(173.54)$ & $0.0001^{*}$ \\
\hline
\end{tabular}

\section{Post-Operative analgesia}

Table 3 shows the comparison of analgesic consumption among three groups; the diclofenac consumption was more in the control group (122.73 mg), compared to nalbuphine group $(68.18 \mathrm{mg})$ and clonidine group $(31.82 \mathrm{mg})$ which is significant.

Table 3: Comparison of three study groups with respect to mean diclofenac doses and tramadol doses by one-way ANOVA

\begin{tabular}{|c|c|c|c|c|c|}
\hline Variables & Summary & Control group & Nalbuphine group & Clonidine group & p-value \\
\hline Diclofenac (mg) & Mean (SD) & $122.73(36.64)$ & $68.18(39.17)$ & $31.82(37.64)$ & $0.0001^{*}$ \\
\hline Tramadol (mg) & Mean (SD) & $19.70(5.73)$ & $6.06(2.88)$ & $3.03(2.11)$ & $0.0073^{*}$ \\
\hline
\end{tabular}

Figure 1 shows the diclofenac consumption was maximum at the $4^{\text {th }}$ hour in the control group, in the nalbuphine group it was in between $8^{\text {th }}$ hour to $16^{\text {th }}$ hour. In the clonidine group, it was at the $16^{\text {th }}$ hour.

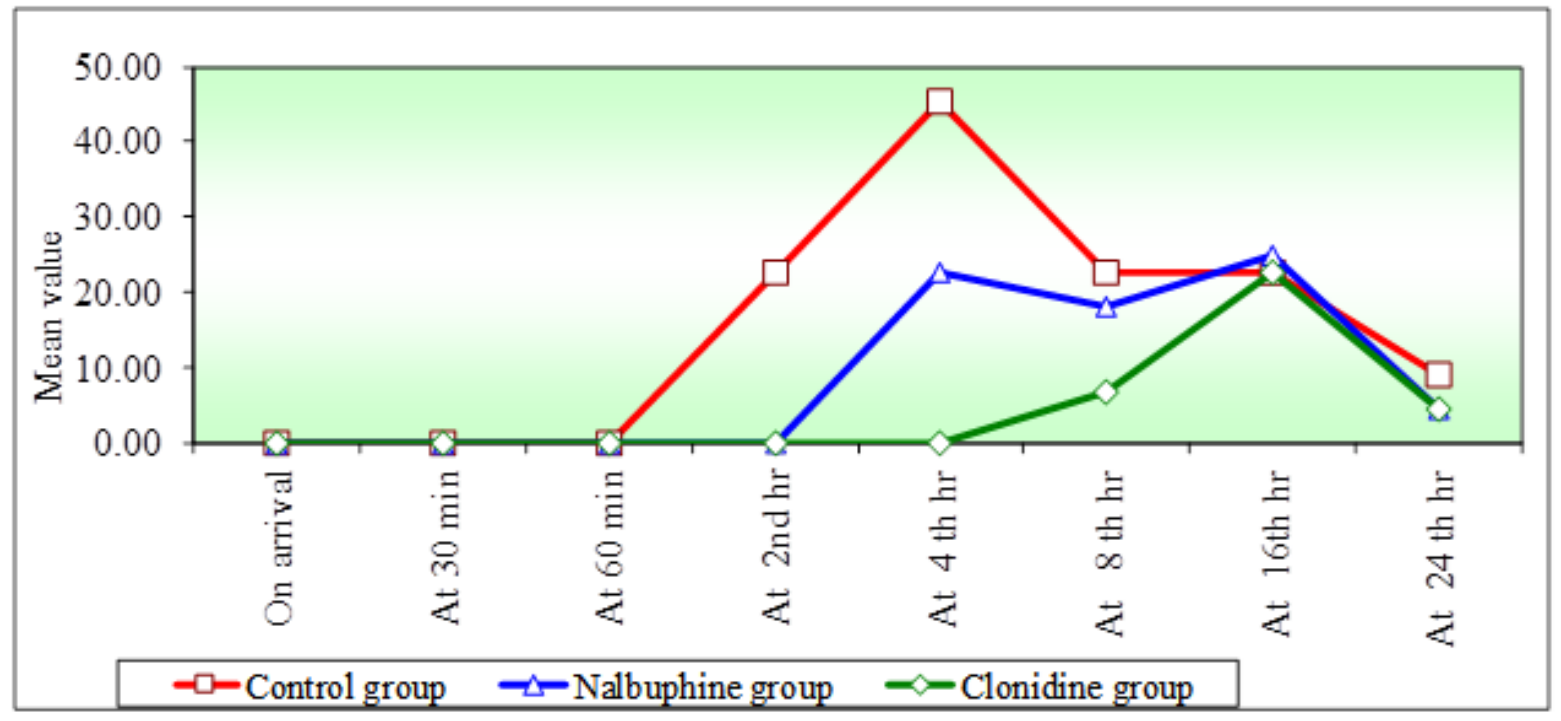

Fig 1: Comparison of three study groups with respect to diclofenac consumption at different time points

The $24 \mathrm{~h}$ VAS score among three groups; control group had more VAS (5.06) $24 \mathrm{~h}$ on, whereas nalbuphine had 4.82 and clonidine group had 4.42 VAS at the same time. (Figure 2) 


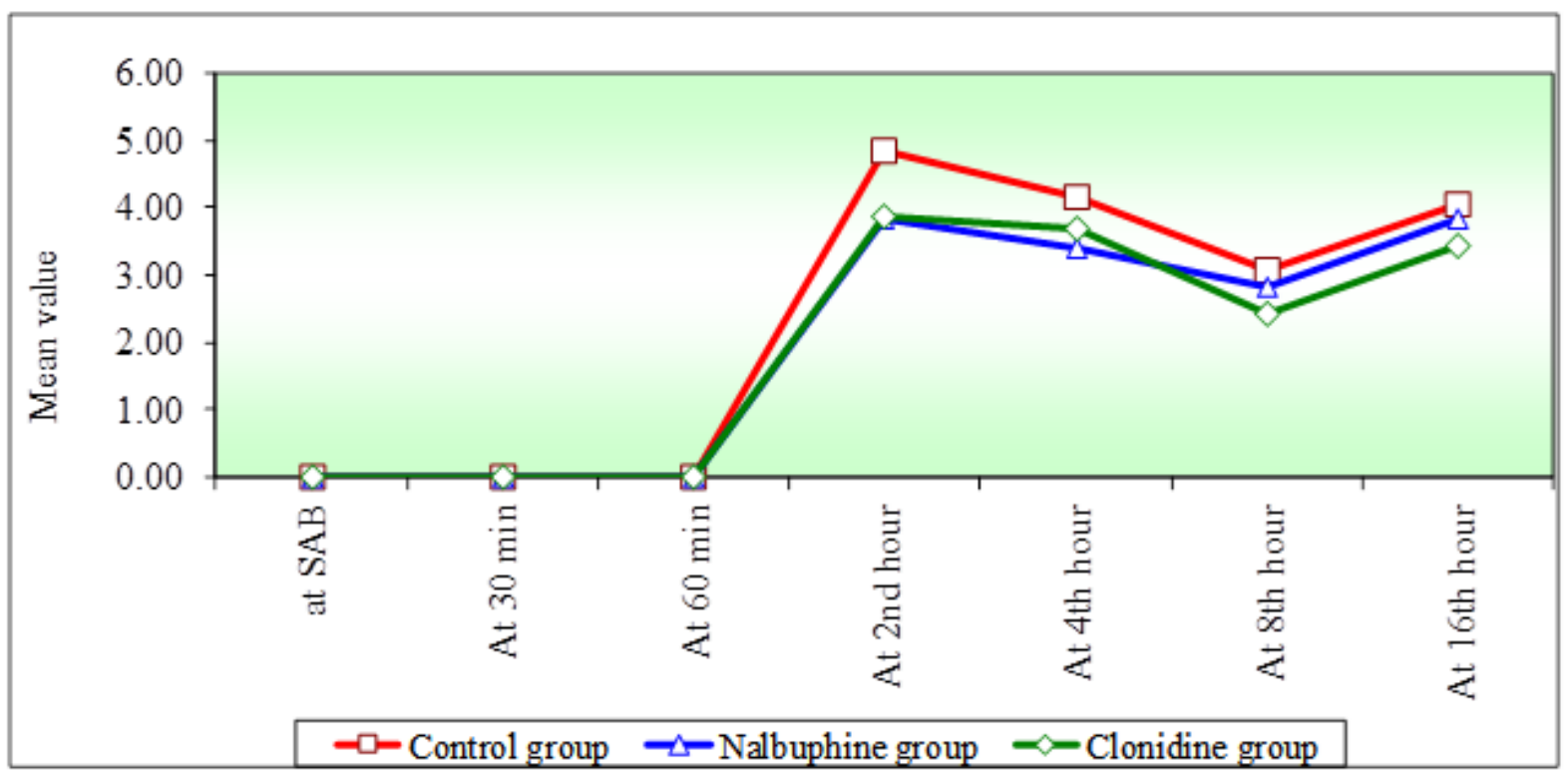

Fig 2: Comparison of three study groups with respect to VAS scores at different time points

Consumption of ephedrine was more in the clonidine group (5.64 mg). (Table 4)
Consumption of ondansetron was more in the nalbuphine group (1.82 mg). (Table 4)

Table 4: Comparison of three study groups with respect to mean doses of different drugs by one-way ANOVA

\begin{tabular}{|c|c|c|c|c|c|}
\hline Variables & Summary & Control group & Nalbuphine group & Clonidine group & P value \\
\hline Ephedrine(mg) & Mean(SD) & $1.27(0.51)$ & $2.00(0.56)$ & $5.64(0.94)$ & $0.0001^{*}$ \\
\hline Atropine(mg) & Mean(SD) & $0.02(0.02)$ & $0.04(0.03)$ & $0.11(0.04)$ & 0.0776 \\
\hline Ondansetron(mg) & Mean(SD) & $0.61(0.25)$ & $1.82(0.35)$ & $0.48(0.23)$ & $0.0018^{*}$ \\
\hline
\end{tabular}

In our study, the consumption of ondansetron in control group was $0.61 \pm 0.25 \mathrm{mg}$ compared to $1.82 \pm 0.35 \mathrm{mg}$ in nalbuphine group and $0.48 \pm 0.23 \mathrm{mg}$ in clonidine group which was statistically very highly significant. The incidence of nausea was $39.39 \%$ in nalbuphine group, $27.27 \%$ in clonidine group, when compared to $12.12 \%$ in control group which was statistically insignificant. The incidence of vomiting was $30.30 \%$ in nalbuphine group, $12.12 \%$ in clonidine group, when compared to $15.15 \%$ in control group which was statistically insignificant.

\section{Discussion}

Spinal anaesthesia is a well-established technique for lower abdominal, urologic and lower limb surgeries. Many advantages of this technique are well known and widely accepted. Major lower limb orthopaedic surgery is extremely painful. It requires aggressive analgesia during early post operative period.

In recent years, $0.5 \%$ bupivacaine has replaced $5 \%$ lignocaine in spinal anesthesia for its obvious advantages over the latter. However, studies have shown associated haemodynamic instability with higher volumes of $0.5 \%$ bupivacaine. In order to minimize this side effect and to maximize analgesia many adjuvants like opioids eg. morphine, fentanyl and non-opioids like ketamine and clonidine have been used.

Due to lack of studies comparing the intrathecal nalbuphine and intrathecal clonidine, we calculated the equivalent doses of intrathecal nalbuphine and intrathecal clonidine.

(Fournier et al. ${ }^{[9]}$ ) Xavier et al, in 2000, performed a comparative study to evaluate post operative analgesia and adverse effects after using three doses i.e. $0.2 \mathrm{mg}, 0.8 \mathrm{mg}$,
$1.6 \mathrm{mg}$ of intrathecal nalbuphine or morphine $0.2 \mathrm{mg}$ given for caesarean section along with bupivacaine. The longest durations of complete and effective analgesia among the nalbuphine-treated groups were provided by $0.8 \mathrm{mg}$ added to bupivacaine. They concluded that $0.8 \mathrm{mg}$ of intrathecal nalbuphine improves intraoperative analgesia and prolongs early postoperative analgesia without increasing risk of side effects.

Demographic parameters gender, mean age, ASA physical status, BMI were comparable in all the three groups. These parameters were kept identical in all groups to avoid variation in intra and post operative outcome of the patients. In our study mean duration of surgery was comparable in all the three groups.

In our study, the mean onset time of sensory block was $6.73 \pm 2.54 \mathrm{~min}$ for patients belonging to control group, $9.73 \pm 3.06 \mathrm{~min}$ for patients belonging to nalbuphine group and $6.36 \pm 2.03 \mathrm{~min}$ for patients belonging to clonidine group. The time to reach complete motor block was $4.61 \pm 1.54 \mathrm{~min}$ for patients belonging to control group, $6.76 \pm 2.26 \mathrm{~min}$ for patients belonging to nalbuphine group and $6.36 \pm 2.03 \mathrm{~min}$ for patients belonging to clonidine group.

The time duration for the two segment regression of sensory level in control group was $108.73 \pm 19.51$ min compared to $175.33 \pm 42.78 \mathrm{~min}$ in nalbuphine group and $209.06 \pm 56.06$ min in clonidine group which was statistically very highly significant.

Sethi et al. ${ }^{[10]}$, found that addition of $1 \mu \mathrm{g} / \mathrm{kg}$ of clonidine to bupivacaine prolonged the time for two segment regression (218 $\mathrm{min}$ ) when compared to control group (136 $\mathrm{min})$. The addition of $1 \mu \mathrm{g} / \mathrm{kg}$ of clonidine to bupivacaine prolonged 
the motor block (205 min) when compared to control group (161 min). The duration of analgesia for the clonidine group was 614 (480-1140) minutes.

Shakooh et al. ${ }^{[11]}$, concluded that time for two segment regression for intrathecal nalbuphine was $218.50 \pm 34.72$ minutes. In our study addition of nalbuphine prolonged time for two segment regression by $67 \mathrm{~min}$ compared to control group.

In our study, the time for motor blockade regression to Bromage 0 in control group was $186.39 \pm 32.42 \mathrm{~min}$ compared to $175.06 \pm 33.33 \mathrm{~min}$ in nalbuphine group and $213.06 \pm 40.35 \mathrm{~min}$ in clonidine group. Santiveri et al. ${ }^{[12]}$ showed that the addition of intrathecal clonidine of $75 \mu \mathrm{g}$ prolonged the duration of motor block in the clonidine group $(165.5 \pm 30.6 \mathrm{~min})$ than in the control group (139.7 $\pm 40.4 \mathrm{~min})$.

In our study, the duration of analgesia in control group was $212.97 \pm 16.33 \mathrm{~min}$ compared to $377.06 \pm 33.89 \mathrm{~min}$ in nalbuphine group and $493.55 \pm 173.54$ mins in clonidine group which was statistically very highly significant. The consumption of diclofenac in control group was $122.73 \pm 36.64 \mathrm{mg}$ compared to $68.18 \pm 39.17 \mathrm{mg}$ in nalbuphine group and $31.82 \pm 37.64 \mathrm{mg}$ in clonidine group which was statistically very highly significant. And use of second rescue analgesic tramadol in control group was $19.70 \pm 5.73 \mathrm{mg}$ compared to $6.06 \pm 2.88 \mathrm{mg}$ in nalbuphine group and $3.03 \pm 2.11 \mathrm{mg}$ in clonidine group. Diclofenac consumption was maximum at the $4^{\text {th }}$ hour, in the nalbuphine group it was between $8^{\text {th }}$ hour to $16^{\text {th }}$ hour. In the clonidine group, it was at the $16^{\text {th }}$ hour.

In the present study, there was significant reduction in the visual analogue score of the patients in the clonidine group and the nalbuphine group in comparison with higher VAS in the control group. Rescue analgesic consumption was more in the control group compared to other groups. VAS in nalbuphine group and clonidine group were comparable, but use of rescue analgesia was more in the nalbuphine group (statistically significant).

In our study clonidine group had better post operative analgesia compared to both nalbuphine and control group.

Boussofara et al. ${ }^{[13]}$ showed that intrathecal clonidine improved the postoperative VAS as compared to the control group.

The haemodynamic parameters like heart rate and blood pressure were monitored peri-operatively.

In our study, the baseline heart rate in the control group was $81.42 \pm 11.45 \mathrm{bpm}$, the nalbuphine group was $80.67 \pm 14.04$ $\mathrm{bpm}$ and in the clonidine group was $83.91 \pm 12.26 \mathrm{bpm}$ respectively and heart rate was maintained for the first 30 minutes. However, beyond 30 minutes up to 3 hours, there was statistically significant reduction in heart rate in the clonidine group.

The most significant side effects reported about the use of intrathecal $\alpha_{2}$ adrenoreceptor agonists are bradycardia and hypotension. In the present study, these side effects were clinically significantly seen in the clonidine group when compared to the other two groups and thus a higher amount of atropine and ephedrine were utilized in the clonidine group when compared to the other groups.

\section{Conclusion}

We studied postoperative analgesic effects of intrathecal nalbuphine and intrathecal clonidine in patients undergoing elective lower limb orthopedic surgeries and found that intrathecal clonidine $60 \mu \mathrm{g}$ is a better adjuvant compared to intrathecal nalbuphine $0.8 \mathrm{mg}$. However intraoperative haemodynamic stability is better with the intrathecal nalbuphine $0.8 \mathrm{mg}$.

\section{References}

1. Rodgers A, Walker N, Schug S, et al. Reduction of postoperative mortality and morbidity with epidural or spinal anaesthesia: results from overview of randomised trials. Br J Anaesth 2000; 321(7275): 1493.

2. Greene NM. Distribution of local anesthetic solutions within the subarachnoid space. Anesth Analg. 1985; 64:715-730.

3. Jagtap S, Chhabra A, Dawoodi S, Jain A. Comparison of intrathecal ropivacaine-fentanyl and bupivacainefentanyl for major lower limb orthopaedic surgery: A randomised double-blind study. Indian J Anaesth. 2014; 58:442-6.

4. Pitkänen M, Rosenberg PH. Local anaesthetics and additives for spinal anaesthesia - characteristics and factors influencing the spread and duration of the block. Best Practice \& Research Clinical Anaesthesiology. 2003; 17(3):305-322.

5. Tan PH, Chia YY, Lo Y, Liu K, Yang LC, Lee TH. Intrathecal bupivacaine with morphine or neostigmine for postoperative analgesia after total knee replacement surgery. Can J Anaesth 2001; 48:551-6.

6. Eisenach JC, Carpenter R, Curry R. Analgesia from a peripherally active kappa-opioid receptor agonist in patients with chronic pancreatitis. Pain. 2003; 101:8995.

7. Eisenach JC, De Kock M, Klimscha W. alpha (2)adrenergic agonists for regional anesthesia- a clinical review of clonidine (1984-1995). Anesthesiology. 1996; 85(3):655-74.

8. Sethi BS, Samuel M, Sreevastava D. Efficacy of Analgesic Effects of Low Dose Intrathecal Clonidine as Adjuvant to Bupivacaine. Indian J Anaesth 2007; 51:415.

9. Fournier R, Van Gessel E, Macksay M, Gamulin Z. Onset and offset of intrathecal morphine versus nalbuphine for postoperative pain relief after total hip replacement. Acta Anaesthesiol Scand. 2000; 44:94045 .

10. Sethi BS, Samuel M, Sreevastava D. Efficacy of analgesic effects of low dose intrathecal clonidine as adjuvant to bupivacaine. Indian J Anaesth 2007; 51:415.

11. Shakooh S, Bhosle $P$. Intrathecal nalbuphine: An effective adjuvant for post-operative analgesia. Innovative J Med Health Sci. 2004; 4:79-82.

12. Santiveri X, Arxer A, Plaja I, et al. Anaesthetic and postoperative analgesic effects of spinal clonidine as an additive to prilocaine in the transurethral resection of urinary bladder tumours. Eur J Anaesthesiol 2002; 19:589-93.

13. Boussofara M, Carle`s $M$ et al. Effects of intrathecal midazolam on postoperative analgesia when added to a bupivacaine-clonidine mixture. Reg Anesth Pain Med 2006; 31:501-505. 